\title{
Quando a biografia e a ficção se cortejam: Os vários eus das memórias em $O$ sol se põe em São Paulo, de Bernardo Carvalho
}

\author{
Luciana Namorato \\ Indiana University
}

Resumo: Neste ensaio, argumento que, em paralelo à trama ficcional de $O$ sol se põe em São Paulo, Bernardo Carvalho delineia um projeto de narrativa memorialista que tem como característica principal o recurso à ficção. Carvalho define o gênero textual das memórias como comprometido com a verdade emocional dos eventos (em lugar de uma verdade factual) e como instrumental à (trans)formação da identidade de quem narra. Em minha análise, examino as repetidas referências do romance aos disfarces teatrais e à presença estrangeira em São Paulo, e examino como estas referências funcionam como alegorias para o caráter plural e contraditório da identidade pessoal. Para Carvalho, a narrativa memorialista flerta com a ficção com vistas a preservar a verdade emocional dos eventos e a honrar a complexidade do sujeito (auto)biografado.

Palavras-chave: Bernardo Carvalho, biography/biografia, identity/identidade, immigration/imigração, memoir/memórias/, self-knowledge/autoconhecimento

Eu antes tinha querido ser os outros para conhecer o que não era eu. Entendi então que eu já tinha sido os outros e isso era fácil. Minha experiência maior seria ser o outro dos outros: e o outro dos outros era eu. Clarice Lispector, "A experiência maior"

Memory (the deliberate act of remembering) is a form of willed creation. It is not an effort to find out the way it really was-that is research Toni Morrison, "Memory, Creation, and Writing"

\section{<sh1>Introdução}

No artigo "Fiction as Exception", o escritor brasileiro Bernardo Carvalho descreve seu oitavo romance, $O$ sol se põe em São Paulo, publicado em 2007, como um elogio deliberado e explícito da ficção como instrumento de libertação (4). O comentário de Carvalho deve ser interpretado no contexto da frequente associação, por parte da crítica, entre os narradores de seus romances e o autor, ele mesmo. Conforme Carvalho explica, a escolha de personagens estrangeiros ou de ascendência estrangeira em $O$ sol se põe fora a forma por ele encontrada para evitar ver seu romance reduzido a sua história pessoal ("Fiction" 4). O sol se põe é, sem dúvida, uma obra de ficção. ${ }^{1}$ Entretanto, uma leitura cuidadosa revela que, por entre sua trama ficcional, emerge uma reflexão aprofundada sobre o gênero textual das memórias. ${ }^{2}$

Carvalho apresenta a narrativa memorialista como guiada por um tipo peculiar de precisão - distinta da verdade factual—, uma vez que o objetivo principal das memórias seria registrar a verdade emocional dos eventos, ou seja, registrar os sentimentos associados às experiências pessoais relatadas. Seria justamente por essa razão que a narrativa memorialista precisaria recorrer à ficção, uma vez que esta auxilia seu autor a construir e comunicar a verdade emocional dos eventos e dos personagens que retrata. Em meu estudo, examino duas referências 
temáticas fortemente presentes no romance—os vários disfarces utilizados no teatro japonês e a marcada presença estrangeira em São Paulo - e as interpreto como alegorias do caráter múltiplo e paradoxal do ser humano. O enredo de $O$ sol se põe em São Paulo ressalta a natureza plural e misteriosa da identidade pessoal, o que explica por que as narrativas memorialistas são com frequência incapazes de retratar seu sujeito de forma absolutamente coerente, completa ou definitiva. $^{3}$

Minha análise se constrói tomando como base uma porção da fortuna crítica existente sobre a obra de Bernardo Carvalho - mais especificamente aquela em que se examinam, de uma variedade de pontos de vista, os tópicos da imigração, da construção da identidade pessoal e da dicotomia ficção/realidade ${ }^{4}$ - e aprofunda a análise destes temas ao interpretá-los no contexto particular da problematização da narrativa memorialista em $O$ sol se põe em São Paulo. Para estruturar minha análise, recorro às reflexões teóricas da escritora e psicoterapeuta Maureen Murdock em Unreliable Truth. On Memoir and Memory (2003), obra que se indaga sobre as razões que movem a escrita memorialista e enfatiza seu caráter ficcional e incompleto. Apoio-me também nas ponderações da escritora e ativista social afro-americana bell hooks sobre o gênero literário das memórias, desenvolvidas em sua autobiografia intelectual Remembered Rapture: The Writer at Work (1999), assim como nos comentários da escritora afro-americana Toni Morrison sobre o mesmo assunto, apontados em "The Site of Memory” (1987).

\section{<sh1>Setsuko: Uma vida em busca de um narrador}

O narrador-personagem de $O$ sol se põe em São Paulo é um publicitário desempregado, aspirante a escritor e bisneto de imigrantes japoneses. Ele relata um inesperado acordo travado com Setsuko, imigrante japonesa e proprietária de um restaurante no bairro paulistano da Liberdade. Movida pelo desejo de contar suas experiências e vê-las registradas sob a forma escrita, Setsuko contrata o aspirante a escritor como ghostwriter. O produto de seu trabalho, isto é, a narrativa das memórias de Setsuko, coincide com a narrativa de $O$ sol se põe. O romance é tanto a história de Setsuko, como o relato das tribulações e conflitos vividos pelo próprio narrador, enquanto ouvinte e redator da biografia da imigrante japonesa. No romance, Carvalho expõe a confluência entre os terrenos do real e do imaginado para a composição da narrativa memorialista. O autor também discute as várias razões por que um indivíduo narra seu próprio passado, e enfatiza o papel do ato de recordar na construção e transformação da autoimagem deste mesmo indivíduo. 5

Na resenha "Para que serve a literatura?", de 7 de junho de 1999, Bernardo Carvalho examina a publicação em português da coletânea de ensaios Variedades, ${ }^{6}$ de Paul Valéry (18711945), e reflete sobre os comentários do poeta, filósofo e crítico francês a respeito da (in)utilidade da literatura. Carvalho enfatiza que é justamente por não servir para nada que a literatura faz frente à "crença conformista de que todas as possibilidades estão disponíveis no mercado" ("Para que serve" 194). Em sua opinião, a obra literária desperta no leitor o anseio pelo que ainda não existe. Semelhante anseio parece ser a razão que leva Setsuko a relatar seu passado e, neste processo, incluir elementos ficcionais. Ao narrar suas memórias, Setsuko omite detalhes importantes e adiciona indícios falsos; em outras palavras, ela conduz seu ghostwriter a escrever suas memórias como uma obra que combina eventos biográficos com elementos ficcionais. Além disso, o fato de a protagonista contratar um escritor, e não escrever ela mesma suas memórias, adiciona mais uma camada de distorção a sua narrativa. " "Se eu quisesse dar o meu testemunho, podia contar sozinha"”, confessa Setsuko (O sol 33). 


\section{<sh1>0 papel da ficção na narrativa memorialista}

Em $O$ sol se põe em São Paulo, o próprio ato de recordar ou relatar o passado se revela instrumental para a criação da identidade de quem narra. Setsuko constrói sua subjetividade não somente no momento em que vivencia os eventos, mas também quando os recorda e elabora um sentido para eles. Durante o ato de contar suas memórias, o indivíduo seleciona as experiências a serem incluídas, além de preencher as lacunas de suas recordações com a imaginação, moldando, assim, sua autoimagem. Setsuko enfatiza a importância de o escritor por ela contratado não conhecer os eventos ou as pessoas que fazem parte de sua biografia. Seu ghostwriter desconhece totalmente os costumes japoneses e, por isso, é forçado a inventar. Como Setsuko explica a seu ghostwriter, "Preciso de alguém que nunca foi ao Japão. Preciso que você imagine"” ( $O$ sol 33).

A proposta de narrativa memorialista apresentada por Carvalho coincide com a visão da escritora e ativista social afro-americana bell hooks, discutida em Remembered Rapture: "autobiography is a very personal storytelling - a unique recounting of events not so much as they have happened but as we remember and invent them" (hooks 83). Em Unreliable Truth, obra em que se combinam reflexões teóricas sobre o gênero das memórias com exercícios práticos para escritores, Maureen Murdock ressalta a faceta ficcional do texto biográfico e destaca que a memória é corrupta, principalmente porque sua função é fazer sentido do que aconteceu (8). Murdock observa que os seres humanos são criaturas em busca de paradigmas. Por essa razão, o ato de recordar consiste em criar histórias coerentes, capazes de preencher nosso vazio existencial (56). Ou seja, quando um indivíduo reconta seu passado, ele o faz com vistas a criar determinada imagem de sua própria subjetividade ou determinado sentido para suas experiências, sentido este que se encontra estreitamente relacionado a sua verdade emocional (emotional truth), definida como seus sentimentos sinceros sobre um evento (Murdock 164). A tarefa de escrever as memórias consiste em projetar uma verdade emocional, ou verdade de si, em lugar de determinar a verdade do que aconteceu: "memoir is not history", resume Murdock (147). As reflexões de bell hooks e de Toni Morrison sobre a escrita memorialista também incluem referências ao conceito de verdade emocional como seu objetivo primeiro. Na obra de hooks, verdade emocional se traduz como estado mental (state of mind) ou espírito do momento (spirit of a particular moment) (hooks 84$) ;{ }^{7}$ já na obra de Morrison, o conceito de verdade emocional se traduz como verdade (truth), em oposição a fato (fact) (Morrison 193). ${ }^{8}$

Independentemente do termo utilizado- "verdade emocional", "estado mental", ou simplesmente "verdade" - , Murdock, hooks e Morrison igualmente sublinham o caráter criativo e subjetivo da memória. $\mathrm{O}$ ato de recordar transforma os eventos trazidos à tona devido a dois fatores principais: a distância temporal entre a experiência e o momento da recordação ${ }^{9}$; e o papel terapêutico do ato de recordar, que exige com frequência que se reinterpretem os eventos em nome das necessidades ou verdades emocionais do sujeito que rememora. Para Murdock, é o ato mesmo da escrita, e não seu produto (o texto memorialista), que oferece ao sujeito que recorda a oportunidade de curar-se (76). E este processo de cura envolve, com frequência, a reformulação das verdades emocionais antes associadas às experiências passadas. Como resume James Olney, a memória distorce e transforma; de fato, a memória faz tudo, exceto voltar-se em direção ao passado e descrever um evento como ele realmente aconteceu. Nas palavras de Olney,

<ext> Memory distorts and it transforms; it causes some people pain and others happiness, or it brings both pain and happiness at the same time; it apologizes and 
it justifies, it accuses and it excuses; it fails to recall anything and then recalls much more than was ever there-indeed, memory does virtually everything but what it is supposed to do: that is, to look back on a past event and to see that event as it really was. (254)

A presença do elemento ficcional na escrita memorialista se relaciona diretamente com sua capacidade de permitir a quem rememora reescrever seu passado e revivê-lo com mais agência do que quando o experimentou pela primeira vez.

\section{<sh1>Narrativa memorialista: Um encontro com vários "eus"}

Os personagens de $O$ sol se põe em São Paulo vestem um sem-número de máscaras: um ator de teatro, com a ajuda de maquiagem, trajes e máscaras, interpreta vários papéis; Setsuko se esconde por trás de nomes diferentes; um camponês assume a identidade de outro homem e luta na guerra em seu lugar; o narrador se divide entre sua nacionalidade brasileira e sua origem japonesa. Em resumo, o romance é povoado de personagens cujas identidades oscilam e se recusam a estabilizar-se. Nas palavras de Candice Martins Alves sobre $O$ sol se põe, "os personagens escondem suas identidades ao interpretarem diferentes papéis, cada um carregando uma máscara que será revelada com o desenrolar da narrativa" (10). As várias referências do romance ao teatro e a seus disfarces funcionam como uma alegoria para a pluralidade da identidade. A máscara, a maquiagem e o traje do ator de kyogen, capazes de transformá-lo em vários tipos diferentes, prefiguram o desejo da protagonista do romance de usar da narrativa memorialista para experimentar ser quem ela jamais fora e para redefinir-se como indivíduo.

Em sua lista de razões para escrever memórias, Murdock inclui o desejo de voltar a viver o passado, ou seja, "to touch it once again" (111). Ao "tocar" novamente o decorrido, o indivíduo que rememora o modifica. Recordar se torna, assim, sinônimo de criar e viver uma nova versão do passado. Essa é precisamente a imagem de narrativa memorialista projetada por Bernardo Carvalho em $O$ sol se põe em São Paulo. Entre os diversos motivos que levam a protagonista de seu romance a recordar, podem-se listar o desejo de melhor compreender seu passado, a ânsia de reparar erros e o impulso de vingar-se. Além desses motivos, um outro ocupa lugar privilegiado: sua vontade de viver uma vez mais as mentiras de seu passado, que foram eventualmente reveladas como inverdades e corrigidas pelo rumo dos acontecimentos. Setsuko revive estas mentiras como verdades durante sua narrativa memorialista, de forma a resgatar facetas de si mesma abandonadas devido ao desenrolar dos eventos. A ficção é o instrumento encontrado por Setsuko para lutar contra as definições e limitações impostas pela realidade. Através de suas memórias, a imaginação permite a Setsuko reencontrar-se com as diversas mulheres que ela poderia ter sido, assim como com as diversas máscaras por meio das quais os homens que ela amou se deram a conhecer. A reconstituição das mentiras de seu passado permite a Setsuko saborear desdobramentos alternativos — e mais positivos - para suas histórias de amor. Durante o processo de escrita de suas memórias, Setsuko não somente revive a trajetória de sua vida, mas também a modifica; a protagonista não encontra sua identidade, mas a constrói da forma que mais lhe convém no momento mesmo em que recorda.

Setsuko tem segredos a revelar e reparações a fazer, mas seu compromisso com a conclusão de assuntos pendentes se revela menos urgente do que seu anseio por libertar seu passado das limitações da realidade. Não é à toa que uma carta esclarecedora, de autoria de Setsuko, revelando a "verdadeira" identidade dos indivíduos que participam de sua biografia, 
somente venha à tona no penúltimo capítulo do romance. Em O sol se põe em São Paulo, Os esclarecimentos e ajustes pertencem ao segundo plano. Na obra, prevalece o impulso de a protagonista, através de suas memórias, reviver como verdade os vários enganos e as várias mentiras que marcaram sua vida.

O monolitismo da protagonista do romance, isto é, a mulher de identidade bem definida que Setsuko aparenta ser, se desfaz quando a imigrante japonesa se torna personagem de sua narrativa memorialista. Nesta, Setsuko vira uma vez mais a jovem perplexa diante das consequências da guerra, mas também a jovem esposa que suspeita da infidelidade de seu marido, assim como aquela que ainda acredita que seu marido se suicidara; recobra-se também a Setsuko apaixonada por um ator de teatro e desinteressada por seu esposo. Por meio do processo narrativo, Setsuko experimenta novamente uma miríade de identidades que em algum momento lhe eram verdadeiras, mas que terminaram provando-se falsas.

No recontar de seu passado, os enganos e ilusões de Setsuko reconquistam sua autenticidade, e crenças que, em algum momento de sua biografia, já se haviam revelado como falsas impressões se tornam, novamente, possibilidades. Ironicamente, é justo ao adulterar sua memória factual, adicionando a ela elementos da invenção, que Setsuko torna sua narrativa memorialista mais fiel a sua biografia. Isso ocorre porque, no presente da experiência, o indivíduo se depara sempre com uma miríade de possíveis desenvolvimentos ou futuros para si mesmo. No presente da experiência, o futuro ainda é incerto e pluridimensional. Entretanto, quando este mesmo sujeito narra eventos pretéritos, ele lida com uma série linear de eventos, em que os desenvolvimentos e as consequências de suas ações já se encontram estabelecidos. Em Tel quel, Paul Valéry discute precisamente esta limitação do texto memorialista, ${ }^{10}$ que, por narrar o que já aconteceu, perde a riqueza do elemento surpresa que caracteriza a experiência presente. Em sua provocação, Valéry propõe que se imagine escrever uma biografia em que se restaurasse o elemento do acaso a cada instante; em que o narrador, a cada momento da narrativa, soubesse tão pouco do momento seguinte quanto o herói da narrativa sabia naquele instante de sua vida:

<ext> Je ne sais si l'on a jamais entrepris d'écrire une biographie en essayant à chaque instant d'en savoir aussi peu sur l'instant suivant que le héros de l'ouvrage en savait lui-même au moment correspondant de sa carrière. En somme, reconstituer le hasard à chaque instant, au lieu de forger une suite que l'on peut résumer, et une causalité que l'on peut mettre en formule. (Valéry, Tel quel, 349, ênfase no original)

Não sei se alguém já se dedicou a escrever uma biografia tentando, a cada momento, saber tão pouco do momento seguinte quanto o próprio herói da obra sabia no momento correspondente de sua trajetória. Em suma, devolver o elemento do acaso a cada momento, ao invés de forjar uma sequência que possa ser resumida, e uma causalidade que caiba em uma fórmula. (minha tradução)

É justamente esta a proposta da protagonista Setsuko ao compor suas memórias: preservar o elemento surpresa para seu interlocutor e seu leitor; a mesma surpresa que ela, como sujeito biografado, experimentara na época em que ainda não sabia como se desenrolaria sua vida, e com que descobria, dia após dia, qual, entre seus possíveis futuros, se tornaria seu presente.

Para garantir o sucesso de seu projeto, Setsuko busca o escritor ideal: aquele que não sabe nada sobre sua vida. Conforme descreve o narrador, "tudo dependia da minha ignorância e 
não do meu conhecimento. Ela contava com a minha ignorância" ( $O$ sol 26). Por ignorar os eventos da vida de sua biografada, o ghostwriter de Setsuko tem mais facilidade em conferir veracidade às identidades falsas dos personagens de sua história. A sede de Setsuko de narrar seu passado a um estranho tem origem em seu reconhecimento do poder da narrativa de recuperar histórias que, na linearidade de sua biografia, jamais se realizaram. Setsuko narra suas memórias com a liberdade de uma ficcionista, e o faz com o objetivo de vislumbrar e vivenciar os futuros que não lhe foram disponibilizados. Por essa razão, ela precisa de um ghostwriter que desconheça sua biografia, de forma que não contamine suas memórias com a rigidez da realidade. Submetida à verdade factual, a experiência da composição de suas memórias perderia sua maleabilidade, porque os diversos desdobramentos da narrativa que não se materializaram deixariam de ser considerados alternativas viáveis para sua biografia. Como o mapa do império em que a arte da cartografia lograra a perfeição e que, por isso, coincidia ponto a ponto com o império - como Jorge Luis Borges imagina no conto "Del rigor en la ciencia"—o texto biográfico se tornaria mera transcrição do real, ou seja, reprodução de uma oferta já disponível e, por isso, prescindível.

\section{<sh1>O estrangeiro de si mesmo: $O$ encontro com uma identidade múltipla e paradoxal}

Ao confrontar as variações de sua autoimagem esboçadas em sua biografia, Setsuko experimenta uma sensação de deslocamento e incômodo existencial, ou melhor, a suspeita de que sua identidade presente contém em si mesma o seu oposto. Sublinha-se, assim, a natureza volátil e plural da identidade pessoal. No romance, Bernardo Carvalho se utiliza de repetidas referências à presença estrangeira na cidade de São Paulo, assim como ao cosmopolitismo da metrópole brasileira como forma de ressaltar o caráter multifacetado da identidade pessoal.

O personagem-escritor, figura contumaz em outras obras de Carvalho, se faz também presente em $O$ sol se põe em São Paulo, com a diferença de que, neste romance, "a discussão sobre a função de contar histórias se atrela ao tópico do pertencimento, da marca híbrida de um narrador que tem familiaridade com referências culturais distantes, a japonesa e a brasileira" (Chiarelli 71). ${ }^{11} \mathrm{Em} O$ sol se põe, o personagem-escritor se embate constantemente com sua origem estrangeira. É justamente o ato de reconhecer-se como outro de si mesmo que ele mais teme. É possível que sua inabilidade para escrever ficção, de que o narrador tanto se queixa, seja consequência de seu receio de descobrir-se multidimensional através do processo de escrita. A entrada de Setsuko em sua vida lhe renova as esperanças de ingressar na literatura. Seu impulso de escrever é acompanhado por um esforço por fazer as pazes com sua ascendência japonesa, assim como por sentir-se em casa no Brasil, país onde nascera. Ou seja, o ato de escrever subentende a aceitação, por parte do narrador, do caráter plural e contraditório da identidade pessoal, seja dos personagens que constrói, seja dele mesmo.

A princípio, o narrador do romance acreditara que sua transformação em escritor o ajudaria a definir sua autoimagem. Conforme ele mesmo explica, a respeito de sua "obsessão"até então frustrada - por tornar-se escritor,

<ext> Se no início ainda podia parecer uma veleidade adolescente, com os anos acabou se revelando uma reação natural à constatação de que eu tinha esgotado todas as chances de fazer parte deste mundo, de me sentir integrado a ele, e que não bastava falar português, ter nascido e viver no Brasil. ( $O$ sol 21) 
Depois de finalmente virar escritor, no entanto, o narrador se descobre enganado em suas previsões. Ao invés de fortalecer seu enraizamento e oferecer-lhe a segurança de uma personalidade monolítica, seu ingresso no terreno da escrita é acompanhado pelo sentimento oposto do que ele previra. Sua identidade, em vez de consolidar-se, se dispersa e se desintegra mais e mais. Ele, por fim, reconhece seu erro em acreditar que escrever em português seria uma forma de passar a pertencer definitivamente ao Brasil. Escrever em português não acalma sua aflição de não pertencer. Se há algo que sua metamorfose em escritor lhe revela é justamente o oposto: a impossibilidade de ignorar seu passado de imigrante, assim como as facetas contraditórias de sua personalidade. Ao contratá-lo para escrever suas memórias, Setsuko força seu ghostwriter a enfrentar o que ele ao mesmo tempo desconhece e reconhece como seu: a história de seus antepassados, que o chamavam de volta. Escrever literatura não estabiliza sua identidade. Pelo contrário, escrever conduz o narrador a mergulhar em um confronto com quem ele poderia ter sido ou, conforme ele mesmo desabafa, a concluir "de uma vez por todas que estamos todos amaldiçoados, onde quer que seja" ( $O$ sol 22). Seria esta "maldição" a que o narrador se refere o aprisionamento do indivíduo a uma identidade singular, moldada pelo lugar onde nasce ou mora, pelo momento histórico em que vive e pela língua que fala? Seria esta "maldição" a sensação de nunca pertencer integralmente a nenhum lugar, tempo ou língua? Ou seria esta "maldição" a constante alternância entre duas sensações opostas: a de sentir-se aprisionado a determinada identidade, e ao mesmo tempo perseguido pela parcela recalcada, mas não menos genuína, desta mesma identidade?

No romance, a instabilidade da autoimagem do ghostwriter se explica por sua condição de descendente de imigrantes japoneses. ${ }^{12}$ No entanto, semelhante sensação pode advir de quaisquer histórias pessoais que ponham em xeque a estabilidade da identidade. No livro de memórias Hunger: A Memoir of (My) Body (2017), por exemplo, a escritora norte-americana Roxane Gay compartilha sua sensação de desconforto a respeito da visão comumente aceita sobre a obesidade:

<ext> In yet another commercial, Oprah somberly says, "Inside every overweight woman is a woman she knows she can be". This is a popular notion, the idea that the fat among us are carrying a thin woman inside. Each time I see this particular commercial, I think, I ate that thin woman and she was delicious but unsatisfying. And then I think about how fucked up it is to promote this idea that our truest selves are thin women hiding in our fat bodies like imposters, usurpers, illegitimates. (139)

A tentação da busca por um "eu verdadeiro" ocorre, com frequência, em cenários em que o indivíduo se vê dilacerado entre duas visões opostas de si mesmo — no caso do narrador do romance, sua origem e aparência nipônica, e seu nascimento e sua criação no Brasil; no caso de Roxane Gay, seu presente de mulher obesa e seu possível futuro de mulher magra. Semelhante ao argumento de Gay, a identidade do narrador não reside em um "eu" brasileiro, escondido sob seu rosto oriental impostor, nem reside em um "eu" japonês ocultado por uma língua portuguesa usurpadora e ilegítima. Através do exercício da composição das memórias de Setsuko, o narrador de $O$ sol se põe em São Paulo passa a suspeitar que o conceito de identidade pessoal é instável e paradoxal, uma vez que é produto de um constante processo de transformação; em outras palavras, de um jogo de espelhos em que os conceitos de "eu" e de "outro" se confundem, e em que os opostos se atraem e se repelem continuamente. 


\section{<sh1>Identidades em trânsito (e anônimas)}

Na obra de Bernardo Carvalho, os deslocamentos identitários dos personagens são frequentemente análogos à movimentação dos mesmos por diferentes espaços físicos no decorrer das tramas. Em uma entrevista de 2008, o escritor ressalta a importância da viagem para sua obra: "the trips that I took prior to my most recent books were provocations of the experience" (apud Brizuela 15). Para a entrevistadora Natália Brizuela, Carvalho viaja "in order to step outside of himself completely when beginning to write" (14). Em O sol se põe em São Paulo, o deslocamento físico, ou a viagem, faz paralelo à discussão sobre a natureza plural da identidade pessoal.

No enredo do romance, o narrador parte para o Japão em busca de mais informações que preencham as lacunas da biografia de Setsuko (Camps 221). Mas quanto mais ele busca desembaraçar a realidade da ficção, mais as duas se misturam. ${ }^{13}$ Neste aspecto, $O$ sol se põe em São Paulo destoa da grande maioria dos romances memorialistas ou dos depoimentos sobre a presença nipônica no Brasil. Agrupadas sob o rótulo de "literatura de imigração", muitas dessas narrativas, assim como o romance de Carvalho, trafegam no terreno ambíguo entre a biografia e a ficção. No entanto, diferente de $O$ sol se põe, obras como o romance Sonhos bloqueados (1991), de Laura Honda-Hasegawa, e o estudo sociológico O imigrante japonês: História de sua vida no Brasil (1987), de Tomoo Handa, são marcadas pela aposta no processo da escrita como instrumento capaz de promover a reconciliação do imigrante - incluindo o autor e o narrador do romance, seus personagens, assim como seus potenciais leitores-com as perdas e os desafios associados com o deslocamento geográfico e o choque cultural comuns à experiência da imigração. Nas obras de Honda-Hasegawa e de Handa, por exemplo, o registro escrito objetiva contribuir para harmonizar as experiências - não raras vezes desorientadoras - vividas pelo imigrante baixo uma identidade estável e apta a vislumbrar um futuro auspicioso. ${ }^{14}$

Quando se examina a proposta de identidades múltiplas levantada em $O$ sol se põe em São Paulo, a questão do nome é outro motivo que sobressai. Há vários exemplos no romance da ausência de nomes, assim como da ênfase no engano ou mascaramento ao nomear-se alguém. Por exemplo, o nome do narrador do romance nunca é revelado; Michiyo se apresenta como Setsuko; o pai de Jokichi contrata Seiji para que este se passe por Jokichi; Seiji morre durante a Segunda Guerra Mundial carregando o nome de Jokichi; ${ }^{15}$ um criminoso de guerra toma para si a identidade de Seiji; Jokichi se muda para o Brasil onde assume o nome de Teruo. O ato de nomear é caracterizado pela falsidade e efemeridade. Nome e ficção caminham lado a lado. Sandra Sousa argumenta que a questão do nome está, no romance, estreitamente relacionada com as transformações sofridas pela identidade dos personagens (195). ${ }^{16}$ Nas palavras de Sousa,

<ext> Um outro aspecto relacionado com a ausência do nome próprio do narrador tem a ver com a própria questão da narração do enredo. Quem conta, afinal, esta história? O narrador, Setsuko, Michiyo, o escritor Tanizaki, o japonês que lê a carta/romance? . . . Ao não ter um nome próprio, este narrador pode ser anulado, podendo confundir-se com as outras personagens. (191)

O deslocamento identitário dos personagens e do narrador em $O$ sol se põe em São Paulo contribui não somente para a instabilidade do conceito de autoimagem, mas também para a polifonia de uma narrativa fluida, cujo significado se afirma provisório. Como observa Luiz 
Guilherme Sakai, no romance "há deslocamentos no que tange ao território, aos gêneros, aos nomes e aos textos. Este último movimento, relacionado à construção do sentido e funcionando como síntese dos demais deslocamentos mencionados" (37). Semelhante às identidades de seus personagens, sempre plurais e em transição, as tramas imaginadas por Bernardo Carvalho primam por projetar um significado sempre efêmero e plural.

\section{<sh1>O estrangeiro da cidade: Uma São Paulo que deseja ser outra}

O incômodo do narrador de $O$ sol se põe em São Paulo ao reconhecer-se estranho de si mesmo encontra paralelo no espaço onde ele vive, e se manifesta em seus comentários a respeito de São Paulo. A cidade parece sofrer do mesmo "mal" que ele sofre, ou seja, de uma insatisfação com o que é, e de uma vontade de ser outro/outra coisa. ${ }^{17} \mathrm{Na}$ opinião do narrador, a arquitetura paulistana, extremamente eclética, refletiria o desejo de a cidade estar em outro espaço e tempo, assim como a inviabilidade desta fantasia. Para ele, São Paulo

<ext> é uma cidade que quer estar em outro lugar e em outro tempo. . . . As mansões mouriscas e ecléticas do começo do século XX (a maioria derrubada) e os prédios mediterrâneos, neoclássicos, florentinos e normandos construídos há poucas décadas revelam o atraso do presente. ... [É] disso que as ruas de São Paulo tentam convencer quem passa por elas: que está em outro lugar, num esforço inútil de aliviar a tensão e o incômodo de estar aqui, o mal-estar de viver no presente e de ser o que é. ( $O$ sol 16)

A forte presença imigrante em São Paulo contribui para o choque entre diversas tradições. Na interpretação do narrador, o bairro japonês da Liberdade, por exemplo, exemplificaria a vontade de a cidade passar pelo que não é. E explica: "Cada imigrante, achando que transplantava o estilo da sua terra e dos antepassados, acabou contribuindo para a caricatura local. . . . Não é só que esteja tudo fora do lugar. Está tudo fora do tempo também" (O sol 15-16). A falsa modernidade da cidade e a tentativa de seus imigrantes nela reproduzirem a sua pátria natal geram no narrador uma sensação de horror, "de não caber neste mundo" ( $O$ sol 29). Trata-se do horror de descobrirse desconhecido de si mesmo, de ver-se incapaz de compreender-se totalmente. A aversão do narrador pela cidade de São Paulo deriva de sua identificação com ela, isto é, da suspeita de que, como ele mesmo, a cidade é várias ao mesmo tempo. ${ }^{18} \mathrm{O}$ narrador e a cidade se revelam, assim, multifacetados, instáveis e sempre à beira de tornarem-se outros de si.

\section{$<$ sh1>Conclusão}

Em $O$ sol se põe em São Paulo, Setsuko consegue multiplicar-se através do ato de rememorar, e revive a experiência das várias mulheres que ela desejara ser. O narrador, por sua vez, admite, na conclusão de seu trabalho como ghostwriter, a impossibilidade de optar por uma origem singular que o defina. $\mathrm{O}$ reconhecimento de uma identidade múltipla liberta a protagonista e o narrador de qualquer compromisso com quem se imaginaram ser no passado ou imaginam ser no presente. $O$ sol se põe é justamente a história dos que não se conformam. Nela, narrando à sombra — ou à revelia — do que são, homens e mulheres se fazem passar por outros em uma tentativa de convencerem-se a si próprios e aos demais de que é possível por fim conhecerse. No encontro com seus antípodas, personagens distantes percebem ter mais em comum entre si do que a princípio imaginaram, e concluem que às vezes o oposto do que acreditam ser é a 
imagem com que mais se parecem. Conforme o narrador do romance ressalta, citando o escritor japonês Junichiro Tanizaki (1886-1965), "a beleza oriental nasce das sombras projetadas" (apud Carvalho, $O$ sol 165). Neste romance, as sombras de Setsuko se projetam nas páginas de um romance em composição. As versões da protagonista que não vingaram, ou seja, os sóis que se puseram em sua biografia, nascem uma vez mais diante dos olhos do leitor.

Bernardo Carvalho inclui, como prólogo de seu romance, a tradução ao português de uma passagem da aula inaugural de Paul Valéry na Universidade de Oxford, Inglaterra, ministrada em 1939, intitulada "Poetry and Abstract Thought": "estranhos discursos, que parecem feitos por um personagem distinto daquele que os diz e dirigir-se a outro, distinto daquele que o escuta" (apud Carvalho, $O$ sol 7). Nesta passagem, Valéry se refere à transformação por que os pensamentos passam ao serem convertidos em discurso poético, discurso este que, para o poeta francês, é distinto da fala comum ("ordinary speech") e versa sobre coisas ausentes ("which never speaks but of absent things or of things profoundly and secretly felt") (Valéry, "Poetry and Abstract Thought" 63). Em O sol se põe em São Paulo, Bernardo Carvalho sugere que a escrita memorialista, assim como Valéry propusera a respeito da poesia, também pressupõe a despersonalização, ou melhor, a repersonalização, tanto de seu emissor como de seu receptor. É a literatura criando e atendendo a suas necessidades particulares; é a história de um personagem que se reconhece (em) um estranho; é o discurso dirigindo-se a um leitor que, de repente, se descobre outro, desconhecido daquele que há pouco lia.

\section{NOTAS}

${ }^{1}$ A obra é descrita por parte da crítica como um exemplo de autoficção, gênero em que um narrador-personagem descreve suas experiências pessoais e cria a ilusão de uma narrativa autobiográfica. A esse respeito, Edward King observa: "Carvalho's narratives are frequently woven out of diary entries and letters, drawing attention to the process of writing the self. His fictions allude suggestively to biographical details about the author while in interviews he criticizes what he sees as an autobiographical tendency in the contemporary prose fiction of Brazil and insists that his texts problematize the genre of autoficção (autofiction)" (97).

${ }^{2}$ Neste ensaio, utilizo os termos memórias e narrativa memorialista como sinônimos de (auto)biografia e relato (auto)biográfico. Opto por ignorar, no contexto deste estudo, as importantes distinções entre biografia e autobiografia.

${ }^{3}$ No capítulo introdutório de Biography. A Very Short Introducton, Hermione Lee ressalta a natureza incompleta e provisória da narrativa biográfica: "There is a lingering idea of biography as the complete, true story of a human being, the last word on a life. But if it is, rather, a mixed, unstable genre, whose rules keep coming undone, then perhaps the only rule that holds good is that there is no such thing as a definitive biography" (18).

${ }^{4}$ Os ensaios de Stefania Chiarelli (2007), Martín Camps (2012) e Edward King (2015) discorrem sobre o tema da imigração em $O$ sol se põe em São Paulo. Já os ensaios de Sandra Sousa (2010), Luiz Guilherme Sakai (2011), Leila Lehnen (2012), Adenize Aparecida Franco (2015) e Candice Martins Alves (2017) examinam o romance no que tange à pluralidade da identidade, relacionando-a com o tratamento do espaço concreto e figurado na obra.

${ }^{5}$ A proposta de narrativa memorialista delineada por Carvalho em $O$ sol se põe em São Paulo sublinha algumas das limitações inerentes às duas metáforas comumente associadas à escrita biográfica: a metáfora da autópsia e a metáfora do retrato (portrait) (Lee 1-4). A metáfora 
da autópsia pressupõe a investigação de um corpo sem vida, cuja trajetória já foi encerrada; o indivíduo biografado, por sua vez, se acha, não raras vezes, vivo e, por isso, sua história de vida ainda se encontra em construção. Além disso, o indivíduo biografado frequentemente intervém na composição de suas memórias, seja relatando-as da maneira que mais lhe convém, seja escrevendo-as ele/a mesmo/a, o que não se passa com o corpo morto que se submete, inerte, a uma autópsia. Já a metáfora do retrato, ainda que leve em conta a liberdade artística de quem retrata, deixa a desejar por não refletir a natureza plural e contraditória do protagonista das memórias. A pintura é estática e consiste em uma única imagem, enquanto a narrativa biográfica permite que se projetem facetas diversas do indivíduo cuja vida se examina-diversas por retratarem diferentes momentos de sua existência e pontos de vista distintos.

${ }^{6}$ Trata-se da antologia Variedades organizada por João Alexandre Barbosa e publicada pela editora Iluminuras em 1999. A coletânea reúne uma seleção de quinze dos 56 ensaios que compõem a obra Variétés, publicada em cinco volumes entre 1924 e 1944.

${ }^{7}$ A respeito do processo de escrita de sua autobiografia, hooks descreve: "As I wrote, I felt that I was not as concerned with accuracy of detail as I was with evoking in writing the state of mind, the spirit of a particular moment" (84).

${ }^{8}$ No ensaio "The Site of Memory", Morrison explica que, em seu processo de escrita, a distinção crucial não reside na oposição entre fato e ficção, mas sim entre fato e verdade ("fact and truth"), uma vez que um fato pode existir independentemente da inteligência humana, enquanto a verdade depende desta (193).

${ }^{9}$ Maureen Murdock enfatiza a distância temporal como uma das razões para a imprecisão da memória. Em suas palavras, "because the events are not happening in present time, we have to use our imagination to reclaim them. So we can never separate the remembered event from our imagination. They stick together" (12-13).

${ }^{10} \mathrm{~A}$ (auto)biografia é um objeto de recorrente interesse de Valéry. James Olney observa que, em sua obra poética, por exemplo, Valéry projeta um conceito de autobiografia em que o "bio" do poema não é nada mais do que consciência pura, ou seja, não equivale a um retorno do autor ao passado, mas sim a uma intensa consciência de sua existência no presente $(252,255)$.

${ }^{11}$ No ensaio "As coisas fora do lugar", Stefania Chiarelli estuda em detalhe a forma como Carvalho dialoga, na construção de seu romance, com a experiência dos imigrantes, entre eles os decasséguis (nipo-brasileiros que retornam ao Japão em busca de trabalho), como seres abjetos.

${ }^{12} \mathrm{Na}$ crítica sobre $O$ sol se põe em São Paulo que aborda o tema da imigração japonesa, três ensaios se destacam: "As coisas fora do lugar", de Stefania Chiarelli; "Paranoid Orientalism", de Edward King; e "Travel and Japanese Migration to Brazil", de Martín Camps. Chiarelli aborda as conexões entre o tema do estrangeiro e o conceito do (não) pertencimento. King examina o romance no contexto de uma era de informação altamente midiática, associando o tema da "outredade" ao Orientalismo. King interpreta o narrador nipo-brasileiro, sempre a tentar apagar sua identidade cultural e racialmente marcada, como símbolo da precariedade e da impossibilidade de uma subjetividade universal (106). Já o ensaio de Camps descreve como a abordagem do tema da imigração asiática no romance contribui para avançar as discussões sobre as relações multiculturais e as negociações de identidade no Brasil atual (217).

${ }^{13}$ Semelhante impulso de buscar materiais concretos, de forma a garantir a veracidade da narrativa, aparece em outro romance do autor, Nove noites (2002). Em Escritas de si, escritas do outro, Diana Klinger examina a forma como Carvalho trabalha com materiais documentais em 
Nove noites para ironizar os limites do ficcional e desafiar as separações binárias entre realidade e ficção.

${ }^{14} \mathrm{Na}$ orelha da primeira (e até o momento única) edição de Sonhos bloqueados, lê-se: "Prepare-se para conhecer a história de Kimiko, uma vida igual a de milhares de brasileiros. .. . Muitos de seus sonhos foram bloqueados, é verdade . . ., mas a busca da felicidade persiste. Kimiko tem um pouco de todos nós. Kimiko pode ser você". Já em $O$ imigrante japonês: História de sua vida no Brasil (obra também publicada em japonês), Tomoo Handa, autor e ilustrador da obra, declara na introdução que "[a]gora sim, nós, os isseis, podemos morrer tranquilos: os nossos descendentes já têm como vislumbrar o caminho que percorremos, através desta tradução para o português da trajetória de todos os imigrantes japoneses no Brasil"' (xx).

${ }^{15}$ No artigo "De metrópoles e de necrópoles", Adenize Aparecida Franco aborda o conceito de identidades distorcidas no romance, associando-as ao tema da morte como "recomeço e oportunidade de se adquirir outra identidade" (194).

${ }^{16}$ Sandra Sousa, no artigo "CConheces o nome que te deram, não conheces o nome que tens"”, examina em detalhe a relevância do nome para a construção do enredo de $O$ sol se põe em São Paulo e afirma, apoiada pelas reflexões de Roland Barthes desenvolvidas em $S / Z$, que o narrador-personagem do romance manipula a questão do nome de modo a afirmar a identidade pessoal como "algo sempre em construção" (191).

${ }^{17}$ Em "Espaços urbanos contemporâneos", Candice Martins Alves faz um estudo aprofundado da representação do espaço da cidade e de sua transformação em personagem de $O$ sol se põe em São Paulo.

${ }^{18}$ Para um estudo mais detalhado dos conceitos de escritura e deslocamento espacial como metáforas da condição epistemológica e ontológica contemporânea, consultar o artigo "Pôr do sol global", de Leila Lehnen. Nele, a autora volta a atenção para a seleção da cidade de São Paulo como pano de fundo do romance e como instrumento de reflexão sobre as condições de exílio no contexto da globalização.

\section{OBRAS CITADAS}

Alves, Candice Martins. "Espaços urbanos contemporâneos em O sol se põe em São Paulo, de Bernardo Carvalho". ReVeLe: Revista Virtual dos Estudantes de Letras, vol. 3, 2011, pp. $1-15$.

Borges, Jorge Luis. “Del rigor de la ciencia.” El hacedor, Emecé, 1965, p. 103.

Brizuela, Natalia. "Bernardo Carvalho”. Trad. Clélia Donovan, Bomb, vol. 102, 2008, pp. 14-20.

Camps, Martín. "Travel and Japanese Migration to Brazil in $O$ sol se põe em São Paulo by

Bernardo Carvalho". Editado por Ignacio López-Calvo, Peripheral Transmodernities:

South-to-South Intercultural Dialogues between the Luso-Hispanic World and "the

Orient”, Cambridge Scholars Publishing, 2012, pp. 214-26.

Carvalho, Bernardo. "Fiction as Exception". Luso-Brazilian Review, vol. 47, num. 1, 2010, pp. $1-10$.

---. "Para que serve a literatura?" O mundo fora dos eixos. Crônicas, resenhas, ficções, Publifolha, 2005, pp. 194-96.

---. O sol se põe em São Paulo. Cotovia, 2007.

Chiarelli, Stefania. "As coisas fora do lugar: Modos de ver em Bernardo Carvalho". Grupo de Estudos em Literatura Brasileira Contemporânea, vol. 30, 2007, pp. 71-78.

Franco, Adenize Aparecida. "De metrópoles e de necrópoles: Espaços perdidos em $O$ sol se põe 
em São Paulo, de Bernardo Carvalho”. Brasiliana: Journal for Brazilian Studies, vol. 4, 2015, pp. 187-207.

Gay, Roxane. Hunger: A Memoir of (My) Body. Harper Collins, 2017.

Handa, Tomoo. O imigrante japonês: História de sua vida no Brasil. Centro de Estudos NipoBrasileiros, 1987.

Honda-Hasegawa, Laura. Sonhos bloqueados. Estação Liberdade, 1991.

hooks, bell. Remembered Rapture: The Writer at Work. Henry Holt, 1999.

King, Edward. "Paranoid Orientalism in Bernardo Carvalho's O sol se põe em São Paulo". Virtual Orientalism in Brazilian Culture, Palgrave Macmillan, 2015, pp. 97-118.

Klinger, Diana. Escritas de si, escritas do outro: $O$ retorno do autor e a virada etnográfica.

Bernardo Carvalho, Fernando Vallejo, Washington Cucurto, João Gilberto Noll, César Aira, Silviano Santiago. 7Letras, 2007.

Lee, Hermione. Biography. A Very Short Introduction. Oxford UP, 2009.

Lehnen, Leila. "Pôr do sol global: Itinerários urbanos e identidade globalizados em $O$ sol se põe em São Paulo, de Bernardo Carvalho". Editado por Regina Dalcastagnè e Anderson Luís Nunes da Mata, Fora do retrato: Estudos de literatura brasileira contemporânea, Horizonte, 2012, pp. 118-34.

Morrison, Toni. "The Site of Memory". Inventing the Truth: The Art and Craft of Memoir. Editado por William Zinsser, Houghton Mifflin, 1987, pp. 101-24.

Murdock, Maureen. Unreliable Truth. On Memoir and Memory. Seal Press, 2003.

Olney, James. "Some Versions of Memory/Some Versions of Bios: The Ontology of Autobiography". Autobiography: Essays Theoretical and Critical, Princeton UP, 1980, pp. 236-67.

Sakai, Luiz Guilherme. "Identidades plurais em $O$ sol se põe em São Paulo, de Bernardo Carvalho". Kalíope, vol. 7, num. 14, 2011, pp. 29-39.

Sousa, Sandra. “'Conheces o nome que te deram, não conheces o nome que tens': A questão identitária do nome próprio e a experiência nipo-brasileira em $O$ sol se põe em São Paulo, de Bernardo Carvalho". Revista Iberoamericana, vol. 66, num. 230, 2010, pp. 187-99.

Valéry, Paul. "Poetry and Abstract Thought". The American Poetry Review, vol. 36, num. 2, 2007, pp. 61-66.

---. Tel quel. Gallimard, 1943. 